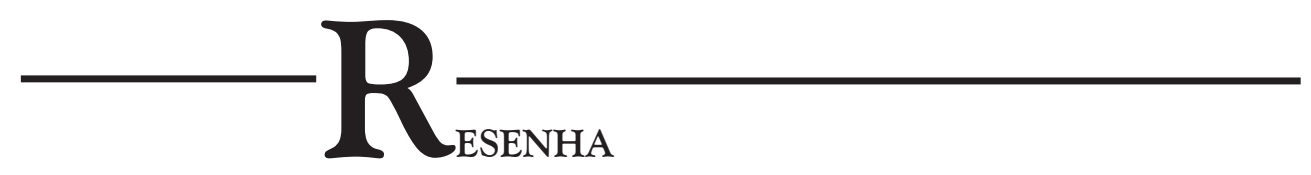

NASCIMENTO, Gilberto. O Reino: a história de Edir Macedo e uma radiografia da Igreja Universal. São Paulo: Companhia das Letras, 2019, 384pp.

Rodrigo de Sá Netto

Universidade Federal Fluminense

Niterói - RJ - Brasil

Orcid: https://orcid.org/0000-0002-7363-0009

\title{
ESCALANDO MONTANHAS: ASPECTOS POLÍTICOS E SOCIAIS DA ASCENSÃO DA IGREJA DE EdIR MACEDO
}

"Você vai fazer coisas muito maiores que subir em árvores, vai subir montanhas". Na cinebiografia romantizada Nada a Perder, Beth Goulart consola o pequeno Edir Macedo, de mãos congenitamente deformadas, alvo de deboche da garotada da pequena cidade fluminense de Rio das Flores. A milionária produção, bancada por empresas como Riachuelo, Cielo, MRV Engenharia, Faculdade das Américas, o grupo Garnero e a própria Igreja Universal do Reino de Deus, é uma esmerada peça apologética sobre o líder inconteste do grupo IURD. Lançado recentemente pela Companhia das Letras, o trabalho do jornalista Gilberto Nascimento (2019), por outro lado, como expresso pela palavra "radiografia" em seu subtítulo, pretende 
esmiuçar o que existe por baixo da imagem que produtos como Nada a Perder buscam projetar de Macedo e de sua Igreja. Ou deveríamos dizer empreendimento?

Sucesso de bilheteria com salas vazias, a própria trilogia Nada a Perder é alvo do olhar penetrante do jornalista, materializado num livro sustentado por quase uma centena de entrevistas. Dentre elas, despontam antigos dirigentes da Universal, como o ex-bispo Ronaldo Didini, mas também pastores, funcionários de empresas controladas pelo grupo Universal, membros do judiciário e acadêmicos. Dedicada à apuração dos fatos, como todo bom jornalismo, a obra é um extenso dossiê sobre Edir Macedo, seus homens de confiança e o império empresarial-religioso que construiu, registrando, por exemplo, que a confortável e sempre aberta cela em que o "bispo" fora brevemente confinado em 1992 pouco se assemelha com o calabouço apresentado na cinebiografia. Em outra parte, são as próprias palavras de Macedo, trocadas com o presbiteriano Caio Fábio, que põem em xeque a idealização de sua imagem. Questionado pela heterodoxia do seu proselitismo, que para Fábio poria em risco a integridade da mensagem bíblica, Macedo respondera que se o erudito colega fisgava almas com camarão, uma iguaria, outros o fariam com minhoca ou mesmo com fezes, sendo esse o seu caso. Num momento de rara sinceridade, Macedo confessara ser esta a "isca" que apeteceria aos frequentadores da Universal, insensíveis assim às palavras de pregadores como Fábio.

O texto de Nascimento também não se furta de investigar o lado mais obscuro da trajetória da IURD que, além das acusações de charlatanismo, curandeirismo e estelionato que levaram à prisão de Macedo, contém ainda suspeitas de pedofilia, assassinatos, adoções ilegais, corrupção, evasão fiscal e até mesmo associação ao tráfico de drogas ilícitas. Este último caso relacionado àquele que talvez seja o pilar do império de Macedo mais importante e extensamente coberto pela obra: a compra da emissora de televisão Record em 1989 por 45 milhões de dólares, quantia além das capacidades arrecadadoras do seu empreendimento, naquele momento ainda estritamente religioso. De acordo com Nascimento, o ex-pastor Carlos Magno de Miranda, no passado responsável pela IURD nos estados de São Paulo e Ceará, teria denunciado que a transação contou com o aporte de um milhão de dólares doados por um comerciante colombiano de entorpecentes. A acusação nunca foi comprovada, ainda que existam alguns indícios, como a real viagem de membros da IURD ao país caribenho na data indicada pelo delator, revela o jornalista.

Mais importante talvez seja a investigação do processo de conversão do não tributável dízimo, por meio de elaboradas manobras financeiras cuja licitude o Ministério Público Federal chegou a questionar, em capital investido em vasto número de atividades lucrativas. Ao longo de seus mais de quarenta anos, o grupo Universal teria construído um conglomerado com quase uma centena de empresas, incluindo emissoras de rádio e TV, bancos, seguradoras, administradoras de cartão de crédito, jornais, hospitais, clínicas, operadoras de plano de saúde, empresas de logística em transporte, de segurança patrimonial, e de bebidas não alcoólicas. Todas conectadas 
por participações societárias mútuas e contratos para prestações de serviços entre si, de modo que grande parte dos lucros do sistema permanece nele contido.

Inaugurado em São Paulo em 2014 e talvez o maior símbolo dessa crescente pujança, o livro oferece uma visita narrada ao Templo de Salomão, dispensando o leitor da taxa de 35 reais para conhecer o monumento, idealizado como uma "Catedral de São Pedro" ecumênica. Isto porque a construção celebra não apenas a magnificência da IURD, mas também seus elos sincréticos com o judaísmo, almejando ainda servir de referência religiosa para brasileiros (e por que não estrangeiros?) de múltiplas confissões. Ilustrativo da prosperidade do grupo, o prédio foi levantado ao custo de 680 milhões de reais, aproximadamente três vezes o valor pago a duras penas pela Rede Record 25 anos antes.

As ligações da Igreja Universal com o mundo partidário também não são negligenciadas. O texto retrocede à eleição de Fernando Collor de Melo, cujo apoio fora acordado em encontro num hotel de Ipanema arranjado por um amigo de Macedo, o empresário e posteriormente deputado federal pelo PRN, Bebetto Haddad. Mas se a intermediação facilitou o diálogo, o apoio de Macedo, importante para o desfecho daquela eleição, de modo algum parece ter sido objeto de difíceis negociações, sendo o dono da IURD até hoje cabo eleitoral de candidaturas moralmente conservadoras e pouco afeitas à crítica capitalista, conclui Nascimento. Nessa mesma toada, é vista de perto a longa relação de antagonismo com o Partido dos Trabalhadores, apesar da inusitada visita de Lula a Macedo em seus dias de cárcere, assim como a capitulação Universal à candidatura petista em 2002, arranjada pelo advogado Márcio Thomaz Bastos, responsável por livrar Macedo da cadeia em 1992, e acordada pela cúpula da organização religiosa, que, segundo o ex-deputado federal Bispo Rodrigues, percebera que os ataques ao PT estariam afastando a população mais pobre. Mas são as relações com Collor e o PSDB as que parecem ter sido mais frutíferas. Sugere o livro, por exemplo, que sem a intervenção do ex-governador de Alagoas e posteriormente de Fernando Henrique Cardoso a compra e a concessão estatal da TV Record teriam sido dificultadas.

Como o apogeu do empreendimento de Macedo parece coincidir com o presente, outra qualidade do texto é a atualidade. Abrange ele fatos acontecidos há poucos meses de ser lançado, como a tentativa de censura de uma revista em quadrinhos pelo sobrinho de Macedo, o prefeito do Rio de Janeiro Marcelo Crivella, e a relação, para lá de amistosa, da IURD com a eleição e o governo de Jair Bolsonaro na presidência da República. Sobre este ponto, diz Nascimento, se o cálculo político fizera Macedo pender inicialmente para Geraldo Alckmin, o fracasso do tucano o levou a abraçar Jair Bolsonaro com ânimo inédito, presidenciável que representaria os interesses da Igreja Universal do Reino de Deus como nenhum outro jamais fizera.

Com serviços nos jornais O Globo, O Estado de S. Paulo e Folha de S.Paulo, além das revistas IstoÉ e Piauí, o repórter entrega um trabalho essencialmente jornalístico, o que significa que a apuração da dimensão factual do fenômeno Edir Macedo e sua IURD é o foco, faltando espaço para análises mais aprofundadas. Isso não quer dizer, 
contudo, que o escrito seja exclusivamente descritivo, contendo algum embasamento teórico. Assim, dois estudiosos do pentecostalismo com grande ressonância na academia foram convidados a contribuir pontualmente, o sociólogo Ricardo Mariano e o cientista da religião Leonildo Silveira Campos.

A colaboração, no entanto, não impede que o texto se concentre nas motivações pessoais do "bispo" para explicar o despontar da maior instituição religiosa "neopentecostal" do Brasil, furtando-se de relacioná-lo com um quadro estrutural mais amplo, fato compreensível numa obra focada na "história de Edir Macedo". Desse modo, a construção do império religioso iurdiano repousaria sobre a ambição e implacável determinação de seu líder, características herdadas do pai, homem violento forjado na guerra pela sobrevivência. Da mesma maneira, o proselitismo típico da IURD, focado na arrecadação do dízimo, e o afinco com que a agremiação se lançou no jogo partidário seriam devidos, novamente, à sede de poder de Macedo, para quem a forma mais elevada de força derivaria da combinação da riqueza com a representação política. A obra não atenta, portanto, para o fato de que a expansão pentecostal e a multiplicação de pastores políticos não são acontecimentos localizados, mas generalizados por todo o mundo e sobretudo pela América Latina.

Largamente negligenciado pela História, esse fenômeno tem recebido atenção especialmente de antropólogos, sociólogos, cientistas da religião e teólogos. Entre eles, um número bastante reduzido e concentrado nas últimas décadas do século XX se propôs a examiná-lo sob o prisma do materialismo histórico, destacando-se o sociólogo Francisco Cartaxo Rolim, autor de Pentecostalismo: Brasil e América Latina $(1994)^{1}$, e o teólogo Hugo Assmann, que assinou A Igreja eletrônica e seu impacto na América Latina $(1986)^{2}$. Em ambos, vemos a tentativa de relacionar o impulso pentecostal no mundo capitalista periférico com o movimento político e ideológico, internacionalmente militante, de grupos cristãos conservadores dos Estados Unidos que, se não estimularam diretamente o surgimento de organizações religiosas por toda a América Latina, hipótese em aberto, certamente lhes serviram de inspiração. Nos dois casos, construtos ideológicos como a Teologia da Prosperidade, saída da pena de intelectuais religiosos norte-americanos, portanto de forma alguma criação de Edir Macedo, são interpretados à luz das contradições do capitalismo contemporâneo que, produzindo em ritmo acelerado trabalhadores precarizados, expropriados e desassistidos, garantiria sua legitimidade aos olhos dos explorados também pela oferta de explicações místicas para mazelas sociais. Afinal, se o Diabo é o causador da pobreza, faz sentido pensar em relações de exploração?

No tempo presente, alcançam proporções inéditas a influência ideológica e o poder estritamente político de grandes organizações pentecostais, como a Igreja Universal do Reino de Deus de Edir Macedo e Marcelo Crivella, mas igualmente a Assembleia de Deus de Marco Feliciano, de Silas Malafaia e do pastor Everaldo Dias. Ademais, mostra-se de forma patente a sua articulação com as demandas dos oligopólios multinacionais e seus associados locais. Fato visível na adesão dessas agre- 
miações ao governo de Jair Bolsonaro, batizado nas águas do Jordão por Everaldo e ungido pelas mãos de Macedo, e à agenda ultraliberal e predadora dos direitos e patrimônios do trabalhador brasileiro consubstanciada no ministério de Paulo Guedes. Em tal panorama, parece urgente a retomada de análises que se proponham a articular o crescimento de agremiações religiosas do feitio da IURD com o quadro social, econômico e político internacional.

Não é disso que se trata o livro de Gilberto Nascimento, que não se dispõe a trazer à luz as estruturas por trás do fenômeno que observa, cabendo agora a profissionais das outras ciências humanas e sociais, interessados em dissecá-las, somar suas contribuições ao esforço do jornalista. A obra sucede, entretanto, em explicar por que Edir Macedo escolheu servir a essas estruturas e como levou a cabo o seu projeto, sendo também útil enquanto embasamento factual para estudos sobre o pentecostalismo brasileiro. Mais do que isso, ao desmontar o personagem que o "bispo" criou para si e expor as entranhas de sua organização, arrisco dizer que contribui imensamente para a desfetichização de um fenômeno que, se é religioso, é talvez até mais político e ideológico.

\section{Notas}

1 ROLIM, Francisco Cartaxo. (1994), Pentecostalismo: Brasil e América Latina. Petrópolis: Vozes.

2 ASSMANN, Hugo. (1986), A Igreja eletrônica e seu impacto na América Latina. Petrópolis: Vozes.

Submetido em: 29/07/2020

Aceito em: 05/01/2021

\section{Rodrigo de Sá Netto* (rdenetto@yahoo.com.br)}

* Doutorando em História na Universidade Federal Fluminense (UFF), Niterói, RJ, Brasil; Técnico em Assuntos Culturais no Arquivo Nacional, Rio de Janeiro, RJ, Brasil; Mestre em História pela Universidade Federal do Estado do Rio de Janeiro (Unirio), Rio de Janeiro, RJ, Brasil. 
